\title{
A Comprehensive Relocation of Earthquakes in Taiwan from 1991 to 2005
}

\author{
by Yih-Min Wu, Chien-Hsin Chang, Li Zhao, Ta-Liang Teng, ${ }^{*}$ and Mamoru Nakamura
}

\begin{abstract}
We have carried out a comprehensive relocation of a total of 267,210 earthquakes in Taiwan that occurred during the past $15 \mathrm{yr}$. We based our relocation process on the earthquake catalog of the Taiwan Central Weather Bureau Seismic Network (CWBSN) and made improvements in three aspects. First, we incorporated a large dataset of the $S$ - $P$ times from 680 Taiwan Strong-Motion Instrumentation Program (TSMIP) stations distributed throughout the island of Taiwan to improve the coverage of earthquakes on the island. Secondly, we added 18 Japan Meteorological Agency (JMA) stations in the southern Ryukyu Island chain to enhance the station coverage for eastern offshore events, especially around the subduction zone northeast of Taiwan. Thirdly, we adopted 3D $V_{P}$ and $V_{P} / V_{S}$ models in predicting the travel times of $P$ and $S$ waves. The effectiveness of these improvements in earthquake relocation can be seen in three aspects: (1) the reduction in the residuals of $P$-wave arrival times and $S-P$ times, (2) a better understanding of the attenuation relationship between the peak-ground acceleration and epicentral distance, and (3) the geologically meaningful patterns of station corrections to $P$-wave arrival times and $S-P$ times.

Online Material: Catalog of relocated earthquakes in Taiwan from January 1991 to December 2005.
\end{abstract}

\section{Introduction}

Taiwan is one of the most seismically active regions in the world. It is situated in the western portion of the Pacific Rim seismic belt. Along the Ryukyu trench east of the island of Taiwan, the Philippine Sea plate subducts northward under the Eurasian plate. Off the southern tip of the island, the South China Sea subplate, part of the Eurasian plate, subducts eastward under the Philippine Sea plate (Tsai et al., 1977). Figure 1 is a schematic diagram showing the major geologic settings in the region. On the southeast side of Taiwan, the Longitudinal Valley, the suture zone of Eurasian and Philippine Sea plates, separates the region into two major tectonic provinces. The eastern side consists of the Coastal Range and several volcanic islands, and it is the leading edge of the Philippine Sea plate. The western province is associated with the Eurasian continental shelf (Ho, 1999), and can be classified into four north-northeast-south-southwest trending tectonic belts. They are, from west to east, the Coastal Plain, the Western Foothills, the Hsuehshan Range, and the Central Range (Fig. 1).

As a result of the regional tectonic movements, most of Taiwan is under a northwest-southeast compression with a

"Present address: University of Southern California, Los Angeles, California 90089. convergence rate of about $8 \mathrm{~cm} / \mathrm{yr}$ (Yu et al., 1997). The Taiwan orogeny, started around 4 Ma (Suppe, 1984), is relatively young on the geological timescale. The island has a high rate of crustal deformation and a strong seismic activity. Since 1994, the Taiwan Central Weather Bureau Seismic Network (CWBSN, Shin, 1992; 1993a), the agency responsible for earthquake monitoring, records about 18,000 events each year in a roughly $400 \times 550-\mathrm{km}$ region. Many significant and damaging events that have occurred in the past decade have been well recorded and carefully studied, for example: the 1998 Reuy-Li $M_{\mathrm{w}} 5.7$ earthquake (e.g., Chen et al., 1999; Wu et al., 2003), the 1999 Chi-Chi $M_{\mathrm{w}} 7.6$ earthquake (e.g., Chang et al., 2000; Shin and Teng, 2001; Teng et al., 2001; Chen, 2003; Chen et al., 2006; Wu and Chiao, 2006; Chang et al., 2007; Wu and Chen, 2007), the 1999 Chia-Yi $M_{\mathrm{w}} 5.8$ earthquake (e.g., Chang and Wang, 2006), the 2002 Hualien $M_{\mathrm{w}} 7.1$ earthquake (e.g., Chen et al., 2004), the 2003 Chengkung $M_{\mathrm{w}} 6.8$ earthquake (e.g., Wu, Chen, Shin, et al., 2006; Hu et al., 2007), the 2006 Taitung $M_{\mathrm{w}} 6.1$ earthquake (e.g., Wu, Chen, Chang, et al., 2006), and the recent Pingtung $M_{\mathrm{w}} 7.1$ earthquake in December 2006.

Among all of those events, the Chi-Chi earthquake was the largest inland earthquake to occur in Taiwan in the twen- 


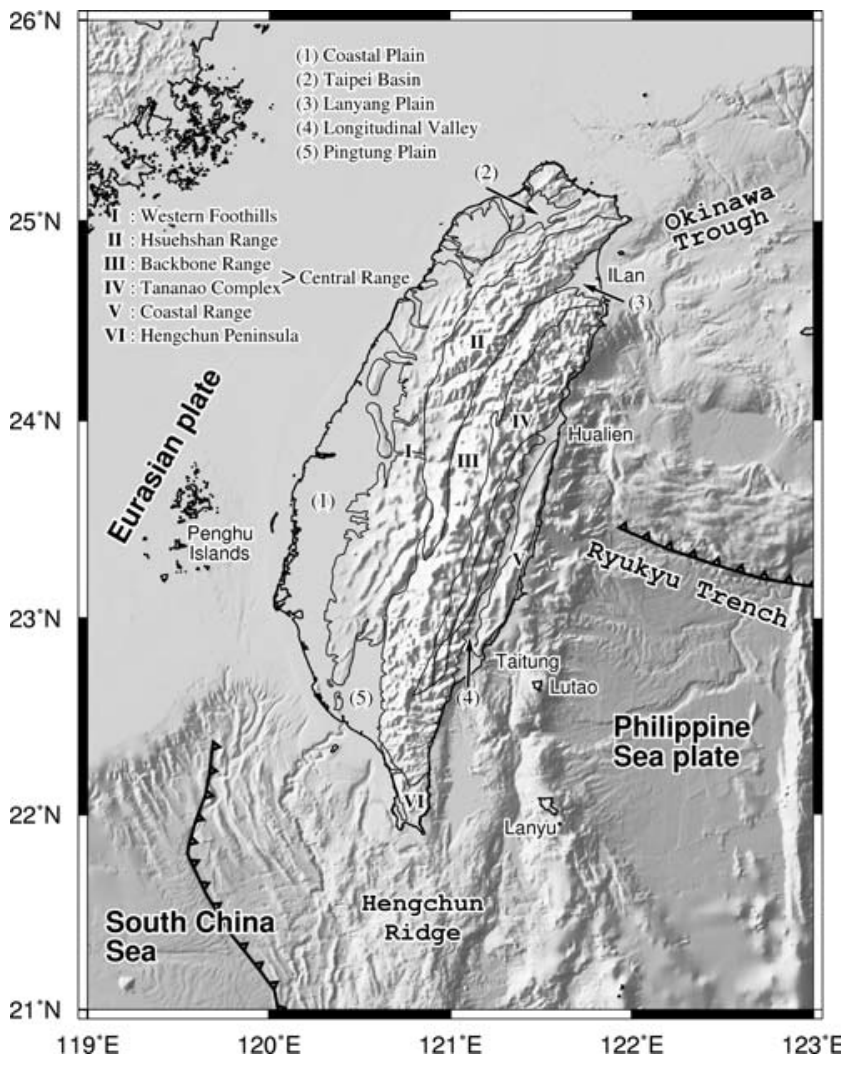

Figure 1. Map showing the topography and geological settings in the Taiwan region.

tieth century. It inflicted severe damage in central-western Taiwan; the strong ground shaking was felt at cities as far as $150-\mathrm{km}$ away from the epicenter and damaged several high-rise buildings in the Taipei basin (Shin and Teng, 2001). It also provided a huge amount of precious near-source strong-motion records for the seismological community (Lee et al., 2001). No early warning was issued before the occurrence of the Chi-Chi earthquake. However, it only took $102 \mathrm{sec}$ for the monitoring system to issue a comprehensive report on the mainshock (location, magnitude, and strong shaking distribution). A detailed post-earthquake examination of the seismicity in the source region revealed that the Chi-Chi earthquake was preceded by a noticeable decrease in regional seismicity rate (Chen et al., 2006; Wu and Chiao, 2006). Chen (2003) has found the activation of moderate-sized earthquakes before the Chi-Chi event and discussed the important implication to the self-organizing spinodal model of earthquakes (Rundle et al., 2000). Wu and Chen (2007) also reported a cycle of the seismic reversal embedded in the changes of seismicity.

An accurate and reliable earthquake catalog is fundamental to many seismological studies. Good earthquake locations depend on the quality of seismic-wave records, the spatial distribution of recording stations, the methodology used to locate an earthquake, and the crustal and upper mantle velocity model employed in the earthquake location algo- rithm. There have been many efforts on the inversions of 3D $P$ - and $S$-wave velocity structures using the CWBSN (Shin, 1992) stations (e.g., Shin and Chen, 1988; Rau and Wu, 1995; Ma et al., 1996; Kim et al., 2005).

Recently, Wu, Chang, et al. (2007) obtained the regional 3D $P$-wave and $V_{P} / V_{S}$ structures by combining a large dataset of $S$ - $P$ times from the Taiwan Strong-Motion Instrumentation Program (TSMIP) records with the $P$ - and $S$-wave arrival times from the CWBSN stations. The TSMIP dataset, which includes more than 600 stations throughout the island, improves the source-station path coverage tremendously and provides much better constraints and resolution in velocity structure determination. The new 3D velocity model ( $\mathrm{Wu}$, Chang, et al., 2007) also motivated us to conduct a 3D relocation study of the regional earthquakes $\left(119^{\circ} \mathrm{E}-123^{\circ} \mathrm{E}\right.$ and $21^{\circ} \mathrm{N}-26^{\circ} \mathrm{N}$ ) published in the CWBSN catalog from 1991-2005 in order to provide a high-quality catalog for earthquake research. In the following sections, we describe the seismic data and the method we used in relocating the earthquakes. Then we present the relocation result and discuss its implications to regional tectonics.

\section{Data and Method}

The CWBSN is the seismic network in Taiwan responsible for monitoring regional earthquakes (Shin, 1992, 1993a). Since 1991, real-time digital recording has been performed. The network consists of a central recording system currently with 71 telemetered stations that are equipped with three-component Teledyne/Geotech S13 seismometers. Including the retired stations, there have been a total of 90 different sites. Figure 2 shows the distribution of the CWBSN stations (solid squares). The CWBSN instruments had been operated in a triggered-recording mode prior to the end of

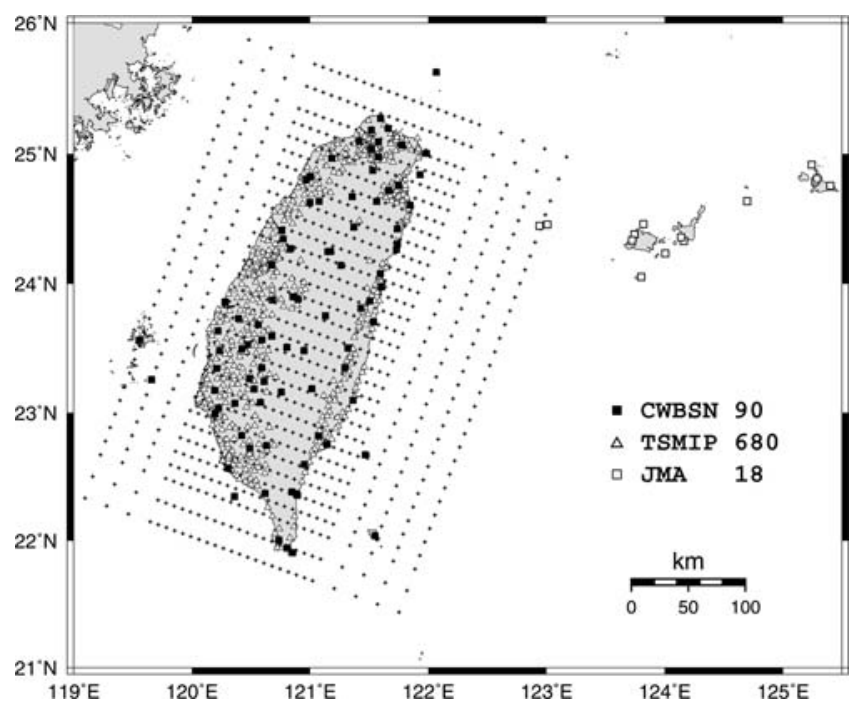

Figure 2. Station distributions of the CWBSN, TSMIP, and neighboring JMA networks. Also shown is the tomography grid used in the 3D structural imaging in Wu, Chang, et al. (2007). 
1993 when continuous recording began. Seismic signals digitized at 12 bits and 100 samples per second from each station are transmitted via dedicated telephone lines to the data center in Taipei. The network is equipped with a system of automatic earthquake detection followed by manual verification. Arrival times of $P$ and $S$ waves are manually picked for earthquake location and Richter local magnitude $\left(M_{\mathrm{L}}\right)$ (Shin, $1993 b)$ determination. The CWBSN has greatly enhanced the earthquake monitoring capability in Taiwan with a magnitude completeness down to an $M_{\mathrm{L}}$ of about 2.0 (Wu and Chiao, 2006). By applying station corrections and proper distance corrections, the CWBSN's $M_{\mathrm{L}}$ can correlate very well with moment magnitude $\left(M_{\mathrm{w}}\right)$ (Wu et al., 2005) for crustal earthquakes. In this study, in order to maintain the consistency with the CWBSN catalog, the magnitudes are adopted as is.

The CWBSN does a good job for routine locations of earthquakes in the Taiwan region. However, the CWBSN event locations are usually not accurate enough for research purposes. The location error for the CWBSN catalog has not been systematically estimated. Previous analyses (Wu et al., 2003; Kuochen et al., 2004) indicate that the hypocentral location error is within $5-10 \mathrm{~km}$ in western and eastern Taiwan, respectively.

We have relocated the CWBSN catalog and improved the accuracy of the earthquake locations using a three-prong approach: first, we include the $S$ - $P$ times from the TSMIP stations (triangles in Fig. 2). The TSMIP consists of 680 digital accelerographs at free-field sites (Shin et al., 2003). Apart from the unpopulated high-mountainous regions, the TSMIP network achieves an average station spacing of about $5 \mathrm{~km}$. It provides very dense coverage for most of the earthquakes in Taiwan. The TSMIP records have not been widely used in location studies in the past because most of the earlier stations were not equipped with absolute timing systems. However, the TSMIP stations always record seismic signals with on-scale waveforms. The $S$ - $P$ times that they provide are not affected by the absolute timing and therefore they provide very robust data that can significantly improve the accuracy in earthquake locations.

Secondly, we incorporate the $P$ - and $S$-wave arrival times of the 18 Japan Meteorological Agency (JMA) stations in the region (Fig. 2) to improve the coverage to the eastern offshore earthquakes. Currently, both the JMA and CWBSN systems use the Global Positioning System (GPS) based timing. Therefore, their arrival times can be jointly utilized. However, there may still be a small timing problem due to the different time-stamping procedures used by the two networks. The CWBSN transfers the seismic signals via digital telephone lines and the time is stamped at the data center in Taipei. Based on our estimation, there may be a delay of a few to a few tens of milliseconds caused by the telemetry latency. For the JMA system, however, the time stamps are attached to the signals at the station in the field and transmitted with the signals. In principle, the JMA network should have no latency delay. Chou et al. (2006) relocated the events between Taiwan and Ryukyu region using the $P$ and $S$ arrivals from both CWBSN and JMA networks. Their results suggest that the time-stamping process operated by CWBSN does not bias the hypocenters significantly with respect to the features concerned in their study. Here, we adopt a station correction approach to remedying the small timingdifference problem. The offshore events are almost always outside the CWBSN network, so the inclusion of the JMA stations significantly improve the azimuthal coverage to the earthquakes occurring off the east coast of Taiwan and therefore enhance the location accuracy there.

Finally, we replace the 1D model in CWBSN locations (Chen, 1995) with the regional 3D $V_{P}$ and $V_{P} / V_{S}$ models of $\mathrm{Wu}$, Chang, et al. (2007) in relocating the earthquakes, and we adopt the 3D location method of Thurber and Eberhart-Phillips (1999), in which theoretical travel times of $P$ and $S$ waves are calculated by $3 \mathrm{D}$ raytracing (Thurber, 1993).

There are a total of 283,241 events in the CWBSN catalog from 1991-2005. We selected events with at least four effective arrivals (with weightings of four or less) and reported by at least three stations. In the end, a total of 267,210 events from 1991-2005 were relocated in this study using the arrival times of 3,102,599 $P$ waves and 2,285,082 $S$ waves from CWBSN, 54,387 $P$ waves and 55,438 $S$ waves from JMA, and 68,251 $S$ - $P$ times from the TSMIP stations.

\section{Assessment of Relocation Quality}

A total of 267,210 earthquakes have been relocated in this study. Figure 3 shows the travel-time residuals for $P, S$, and $S-P$ before and after the relocation. Yellow and blue clouds show readings of high and low weightings, respectively. For the CWBSN locations using a layered 1D model, the travel-time residuals have the means and standard deviations of $0.054 \pm 0.428,-0.308 \pm 0.577$, and $-0.134 \pm$ $0.573 \mathrm{sec}$ for $P, S$, and $S-P$ times, respectively. Figure $3 \mathrm{a}$ also shows clearly that the travel-time residuals for the CWBSN 1D locations do not have a zero mean. In particular, the $S$-wave residuals are biased toward negative in the epicentral distance range from $0-300 \mathrm{~km}$. $S$ - $P$ residuals are mostly negative in the epicentral distance range from 0 $120 \mathrm{~km}$. After the relocation using the 3D model with the station corrections, the travel-time residuals have the means and standard deviations of $-0.006 \pm 0.313,-0.004 \pm$ 0.455 , and $0.029 \pm 0.365 \mathrm{sec}$ for $P, S$, and $S$ - $P$ data, respectively, a significant reduction in the travel-time residuals by using the 3D relocation. In particular, the means of $S$ and $S-P$ residuals decreased by 0.3 and $0.1 \mathrm{sec}$, respectively. The standard deviations of the $P, S$, and $S$ - $P$ residuals have also been reduced by about $27 \%, 21 \%$, and $36 \%$, respectively. Figure $3 \mathrm{~b}$ clearly demonstrates that the travel-time residuals after the 3D relocation concentrate closely around zero, and the systematic shifts with distance have been largely removed, with the exception of the $S$-wave arrival times that are still biased towards negative in the epicentral distance 
(a)

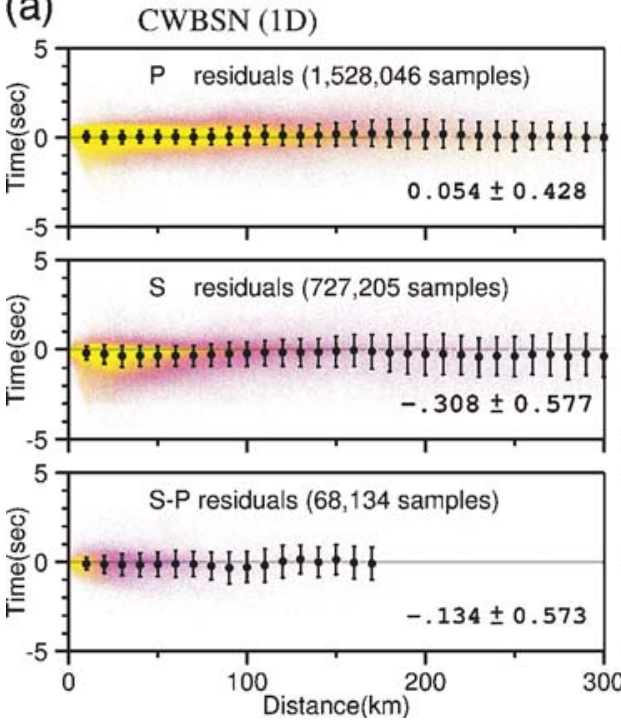

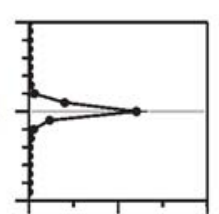
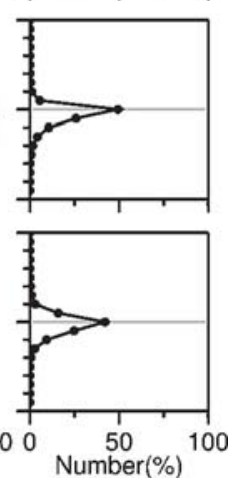

(b)
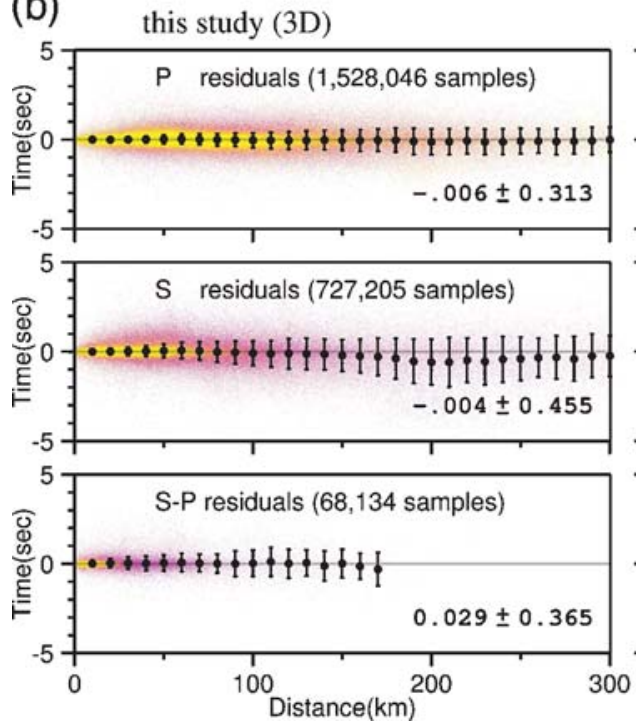

Figure 3. The $P, S$ and $S-P$ residuals of the CWBSN 1D locations and the 3D locations in this study.

ranges from $180-250 \mathrm{~km}$. This is due to the greater difficulty in picking the $S$-wave arrival times for epicentral distances larger than $150 \mathrm{~km}$ because of lower signal-to-noise ratio. In that distance range, the weightings of most of the $S$ arrivals are poor and there are almost no $S$ - $P$ times available. Nevertheless, the overall location quality has been improved significantly in this study.

The combination of the CWBSN arrival times and the $P$ and $S$ times from the nearby JMA stations is an effective approach to improving the earthquake locations in the northeastern offshore area of Taiwan. We can use the GAP values, defined as the largest separation (in degrees) in azimuth between any two azimuthally adjacent stations (Lee and Lahr, 1975), to indicate the improvement in station coverage provided by the JMA stations. The smaller the GAP, the more reliable the epicentral position of an earthquake is in general. Earthquake locations in which the GAP exceeds $180^{\circ}$ typically have large ERH and ERZ values. Here ERH and ERZ are the horizontal and depth location errors in kilometers, respectively. The principal errors are the lengths of the three mutually perpendicular major axes of the error ellipsoid. The ERH is defined as the largest projection of the three principal errors on the horizontal plane, whereas the ERZ is defined as the largest vertical projection of the three principal errors.

Figure 4 shows the hypocentral distributions in the northeastern offshore region and the plots of the root-mean square (rms), ERH, and ERZ versus the GAP for (a) 1D locations from the CWBSN catalog, (b) 3D locations using CWBSN arrival times, and (c) 3D location results using arrival times from both the CWBSN and the JMA stations. Here rms is the root-mean square of the travel-time residuals in seconds. This parameter provides a measure of the fit of the observed arrival times to the predicted ones for a given location. The rms, ERH, and ERZ versus the GAP plots clearly show that the 3D model (Fig. 4b) has significantly improved the earthquake locations, even for most of the events with large GAP values. Furthermore, the inclusion of the JMA stations in the location process has led to reductions in the maximum of GAP and to even more improved location accuracy of offshore earthquakes.

\section{Relocation Result and Discussion}

Figure 5 shows the distribution of the 267,210 relocated earthquakes. (E) A complete catalog of the relocated events is available in the electronic edition of BSSA. The $3 \mathrm{D}$ plot of the hypocentral distribution in Figure 5 provides a clear perspective on the seismotectonic structures in the Taiwan region. There is a wide range of source depths in this region, with deepest sources down to at least $300-\mathrm{km}$ under the subduction zones northeast and south of the island. The Benioff zones are clearly delineated by the distribution of earthquakes.

The earthquake locations from the CWBSN catalog and from this study are compared in map view in Figure 6 and in two vertical profiles in Figure 7. From the map-view comparison in Figure 6, it can be seen that in many event clusters, the relocated earthquakes are more concentrated, with some of the elongated features apparently delineating the fault systems, especially near Hualien and the Longitudinal Valley. On the island, there is a concentration of earthquakes in the central region immediately to the west of the Central Ranges, in the Hualien area on the east central coast, and in the southeast along the Longitudinal Valley suture zone between the Eurasian and Philippine Sea plates. In the comparisons for the two profiles, the subducting slab (in $\mathrm{AA}^{\prime}$ in Fig. 7a) and the Eurasian-Philippine Sea suture zone (in $\mathrm{BB}^{\prime}$ in Fig. 7b) are also better imaged by the relocated events. Notice that in the profiles from the CWBSN catalog, there are horizontaltrending gaps in earthquake source depths (Fig. 7a,b). These 
(a) CWBSN 1D

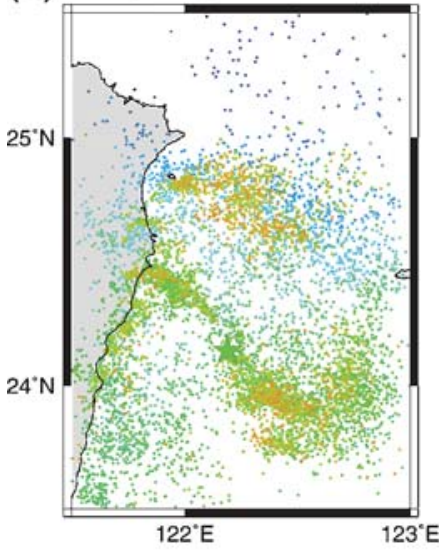

(c) CWBSN \& JMA 3D

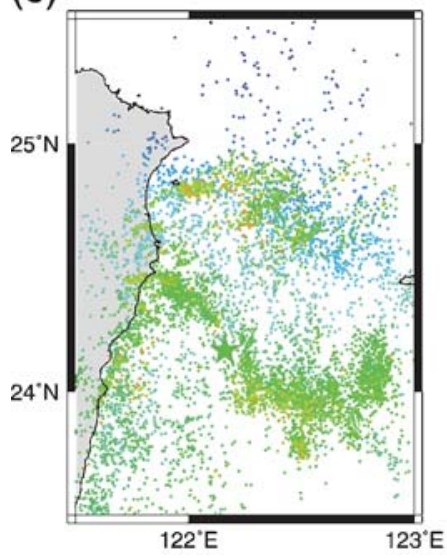

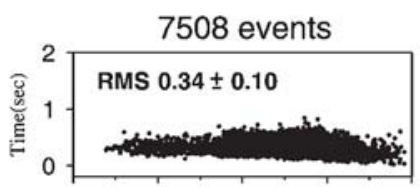
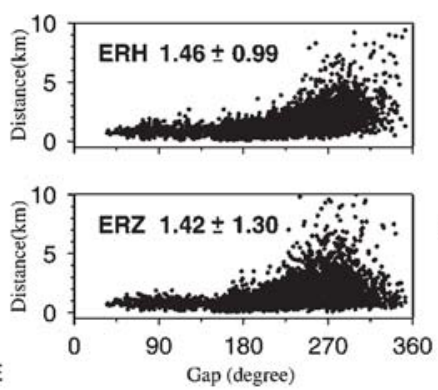

depth $(\mathrm{km})$
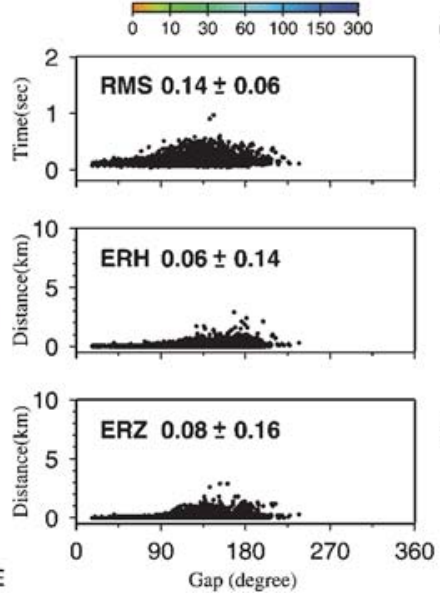

(b) CWBSN 3D
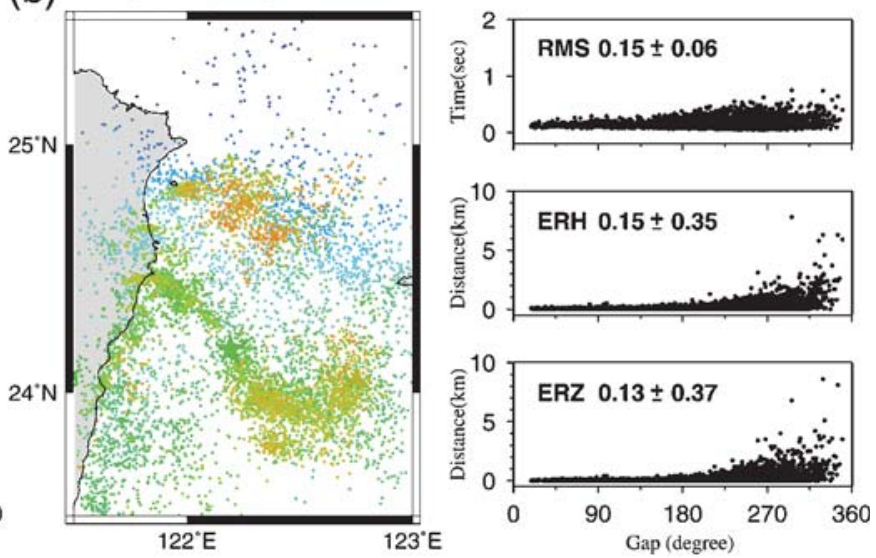

(d) CWBSN vs this study
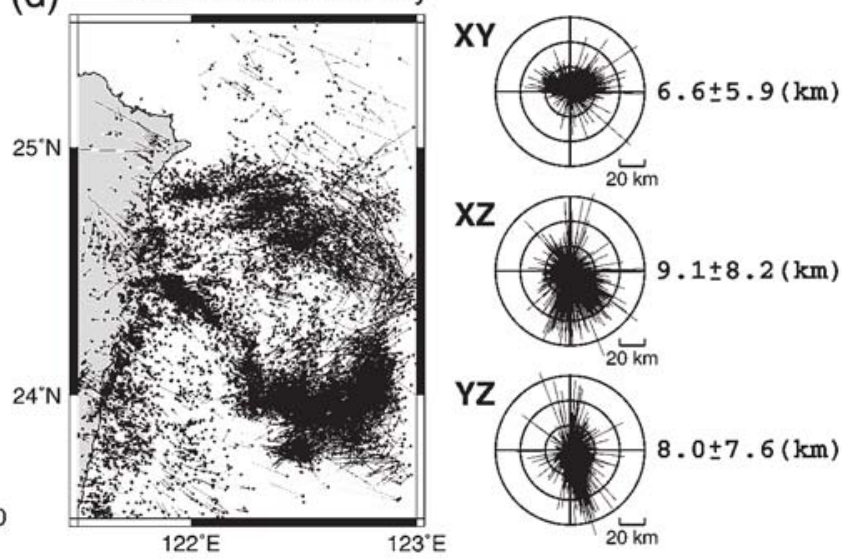

Figure 4. Epicenteral distributions and rms, ERH, and ERZ versus GAP plots for (a) 1D location by CWBSN, (b) 3D location by CWBSN, (c) 3D location by CWBSN and JMA, and (d) location difference between 1D location by CWBSN and 3D location by CWBSN and JMA. Star shows the epicenter of the 2002 Hualien, $M_{\mathrm{w}} 7.1$ earthquake.

are caused by the 1D layered model in CWBSN event location scheme and they have been removed in our 3D relocation.

In the region shown in Figure 4, the majority of the offshore earthquakes are located in the Ryukyu subduction zone

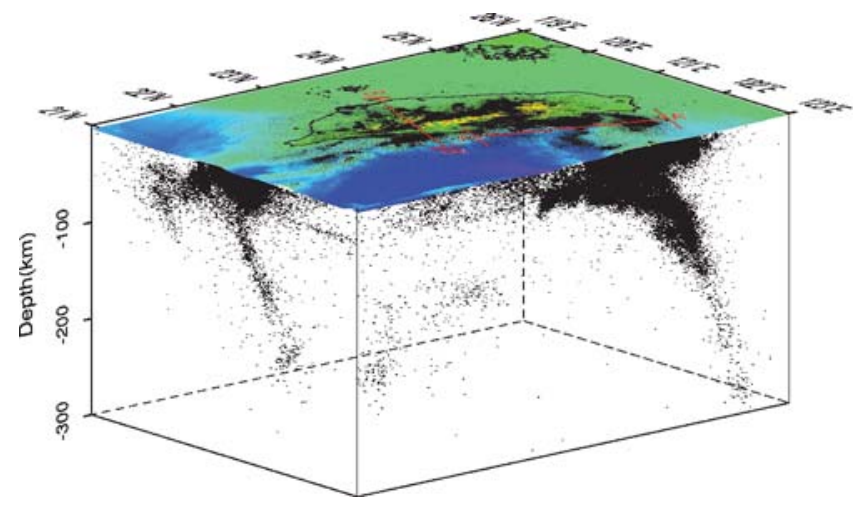

Figure 5. Three-dimensional view of the hypocenter distribution of the 267,210 earthquakes relocated in this study. AA' and $\mathrm{BB}^{\prime}$ show the locations of the profiles in Figure 8.
(Fig. 1). Results based only on data from the CWBSN stations show that the seismic zone seems to continuously extend to the Taiwan Island. However, epicentral distribution changes significantly when the JMA data are involved, especially for the epicentral distribution for the region east of $122^{\circ} \mathrm{E}$ longitude. Figure $4 \mathrm{c}$ shows that the seismic zone is not continuous, but has a gap at the latitude of about $24.0^{\circ} \mathrm{N}$ and between longitudes $122.2^{\circ} \mathrm{E}$ and $123.0^{\circ} \mathrm{E}$. The events form a number of clusters. In particular, a cluster can clearly be seen at about latitude $24.0^{\circ} \mathrm{N}$ and longitude $122.75^{\circ} \mathrm{E}$. The large-scale seismic zone here has a roughly east-west trend at latitude $24^{\circ} \mathrm{N}$. However, there seems to be a bend from $24.0^{\circ} \mathrm{N}-24.3^{\circ} \mathrm{N}$ along the longitude $122.2^{\circ} \mathrm{E}$ (Fig. $4 \mathrm{c}$ ). Along the bend, there is a low in seismic activity, where the $2002 M_{\mathrm{w}} 7.1$ Hualien earthquake occurred. Our relocation moved the hypocenters on average by $4.9 \pm 8.5 \mathrm{~km}$ deeper, by $1.8 \pm 4.7 \mathrm{~km}$ to the north, and by $2.1 \pm 6.9 \mathrm{~km}$ to the east (Fig. 4d). It is obvious that the combination of CWBSN and JMA stations offers a better constraint for earthquake locations in this region. Our relocation result provides a much clearer view of the regional seismotectonics. 


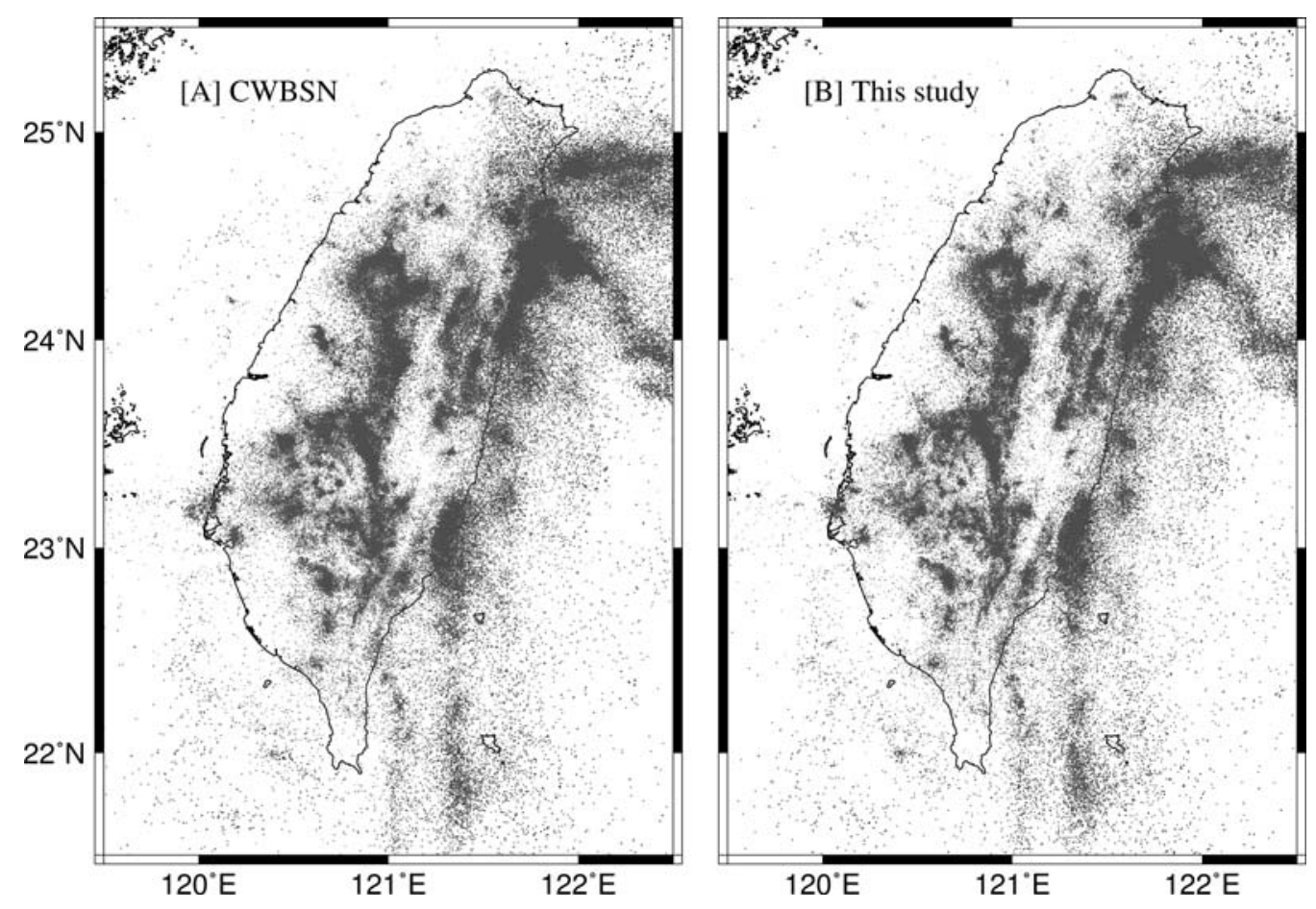

Figure 6. (a) Map view of the epicentral distribution of the earthquakes in the CWBSN catalog. (b) Map view of the epicentral distribution of the earthquakes after relocation in this study.

The 3D structural model and the $S-P$ times from the densely distributed TSMIP stations significantly improve the location accuracy for the earthquakes on the island, which, when taking the earthquakes' focal mechanisms into consideration, also leads to a better understanding of the regional stress field. Figure 8 shows the focal mechanisms of 1635 earthquakes of $M_{\mathrm{L}} \geq 4.0$ from 1991-2005 determined by the genetic algorithm (Wu, Zhao, et al., 2008). In Figure 9, the seismicity of $M_{\mathrm{L}}>2.0$ events with focal depths less than $30 \mathrm{~km}$ relocated in this study is plotted together with the average lateral variation in $P$-wave speed (Wu, Chang, et al., 2007) between the depths of 17 and $21 \mathrm{~km}$ as representation of crust material and a generalized regional stress description. To examine the regions with earthquake clusters, we plot the trends of the compressional and tensional axes as well as the faulting types based on the focal-mechanism results and stress analysis. The analysis of the regional stress field was conducted using the algorithm developed by Michael $(1984,1987)$ based on minimizing the misfit of both nodal planes of each focal-mechanism solution to the best stress tensor to determine the orientation of the principal stresses. Taiwan is a place where the Philippine Sea plate collides with the Eurasia plate in a complex manner (Tsai et al., 1977). In western Taiwan, the Peikang Basement High (PKH; e.g., Mouthereau et al., 2002) is a high-velocity barrier in western Taiwan, and most of the earthquakes occur in the surrounding regions (Fig. 9). Thrust-type focal mechanisms are dominant, but there are also strike-slip events due to a northwest-southeast compressional stress field. A few normal-type focal mechanisms can be found close to the western coastal region. However, many shallow-focus earthquakes with normal-type faults occur in the Central Ranges (on the eastern boundary of this zone). Lin (2002) suggested that the normal faults may result from the effect of active continental subduction and crustal exhumation. We suggest that they are an indication of compressional popup structures (Kuochen et al., 2004), considering the ongoing mountain building in Taiwan and that the region is bounded by thrust faults. The western Central Range is bounded by a wellknown thrust-fault system, including the Chelungpu fault. The eastern boundary of the Central Range is the Longitudinal Valley. Surface geology and geomorphology (Big, 1965; Shyu et al., 2006) suggest the existence of a westdipping thrust-fault bounding the western margin of the Longitudinal Valley. The GPS observation of Johnson et al. (2005) and a study on the seismogenic fault of the 2006 Taitung earthquake (Wu, Chen, Chang, et al., 2006) also support this suggestion.

In southwestern Taiwan, seismicity is lower but the events have focal depths greater than $30 \mathrm{~km}$ with normalfault focal mechanisms (Fig. 9). In this region, the South China Sea plate subducts under the Philippine Sea plate. The normal-fault earthquakes in this zone are likely associated with the bending of the plunging slab.

In northeastern Taiwan, intermediate-depth earthquakes are associated with the Philippine Sea plate subducting under the Eurasia plate (Figs. 1, 8, and 9), whereas shallow events occur as a result of the Okinawa trough opening and the Philippine Sea plate colliding with the Eurasia plate. Thus, 

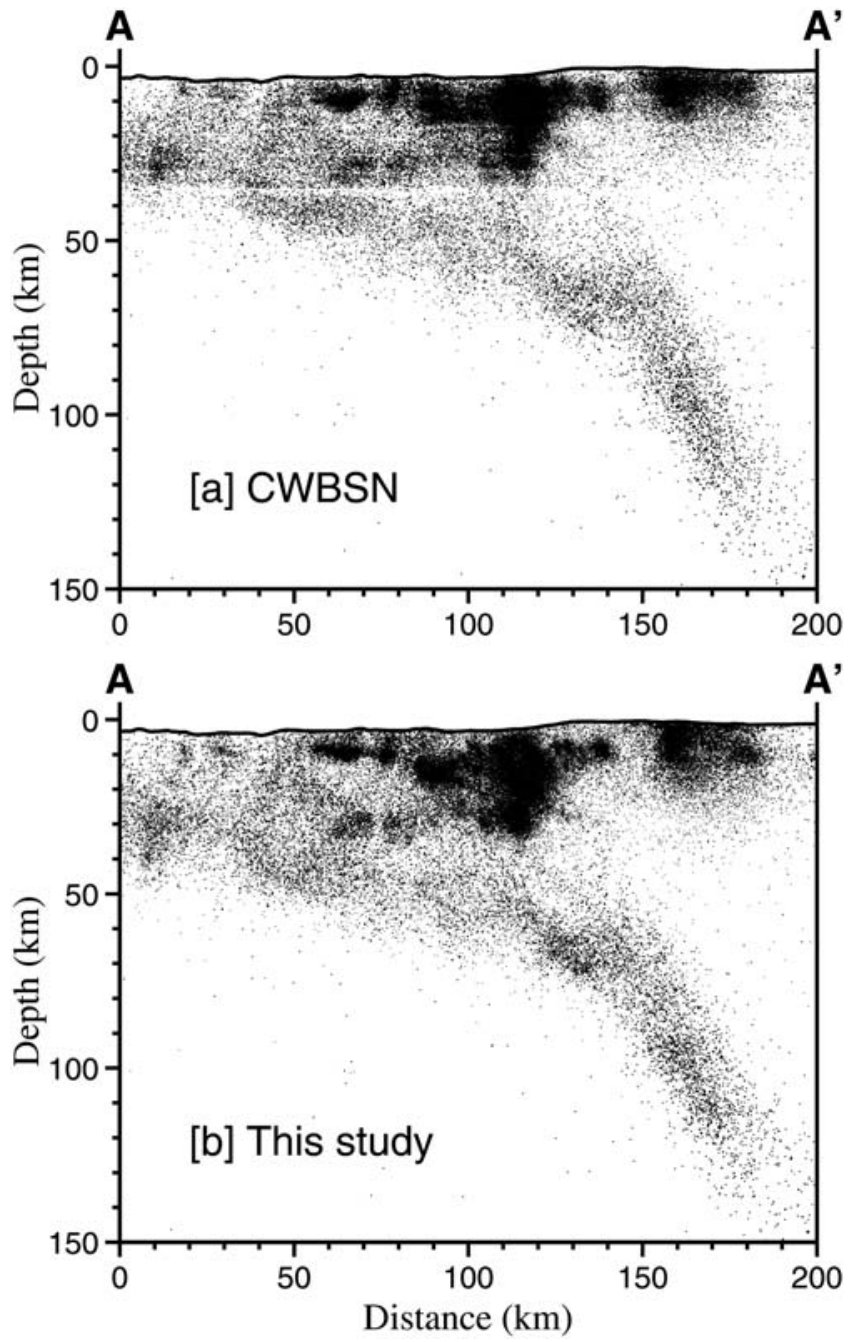
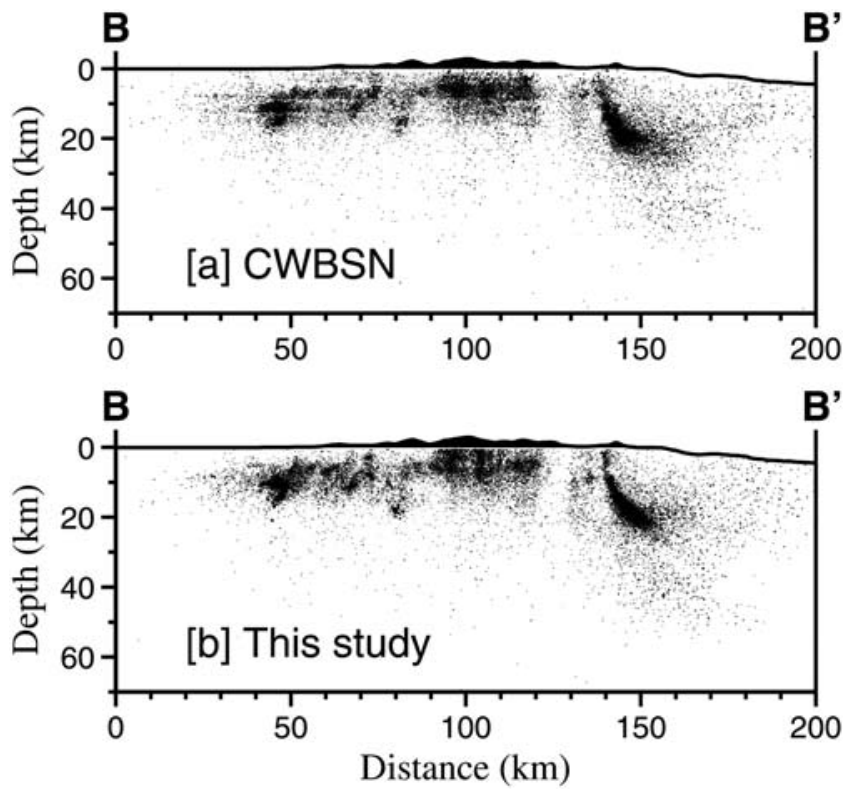

Figure 7. (a) A vertical profile of the distribution of earthquakes in the CWBSN catalog in the subduction zone in northeastern Taiwan. Events plotted here are hypocenters within $40 \mathrm{~km}$ on both sides of the vertical plane. (b) A vertical profile of the hypocentral distribution of the relocated earthquakes in the subduction zone in northeastern Taiwan. Events plotted here are hypocenters within $15 \mathrm{~km}$ on both sides of the vertical plane.

focal mechanisms in this zone vary from thrust in the south (Hualien) to strike slip and normal faults in the north (Ilan).

In southeastern Taiwan, the earthquakes are mainly caused by the collision of the Eurasia plate and the Luzon Island arc on the Philippine Sea plate (Tsai et al., 1977). As shown in Figure 9, a high $P$-wave velocity region is associated with the Philippine Sea plate. Because of the collision, earthquakes there have predominantly thrust-type focal mechanisms (Kuochen et al., 2004; Wu, Chen, Shin, et al., 2006). The Longitudinal Valley is the western boundary of the Philippine Sea plate. It can be seen in Figure 8 that leftlateral strike-slip focal mechanisms are found along the Longitudinal Valley (Wu, Chen, Chang, et al., 2006). Because of the subduction and bending of the Philippine Sea plate (Kuochen et al., 2004), normal and strike-slip faults also exist in this zone. In the Lanyu region, there are some deeper $(\sim 100 \mathrm{~km})$ earthquakes caused by the subduction of the South China Sea plate under the Philippine Sea plate (Tsai et al., 1977).

The refined earthquake locations also offer a good opportunity to study the near-source attenuation of ground motion. An example is shown in Figure 10. Using only the CWBSN stations and the 1D layered model for earthquake locations, the peak-ground acceleration (PGA) versus hypocentral distance plots do not show any discernible attenuation relationship (Fig. 10a). Combining the TSMIP's $S$ - $P$ differential times and the 1D layered model in locations helps bring out the attenuation of PGA with hypocentral distance (Fig. 10b). Using the CWBSN stations and the 3D structural model in relocation result in an even better attenuation relation (Fig. 10c). However, when the 3D model and the TSMIP's $S$ - $P$ times are jointly used in earthquake locations, a much better attenuation of PGA with hypocentral distance can be obtained (Fig. 10d). 


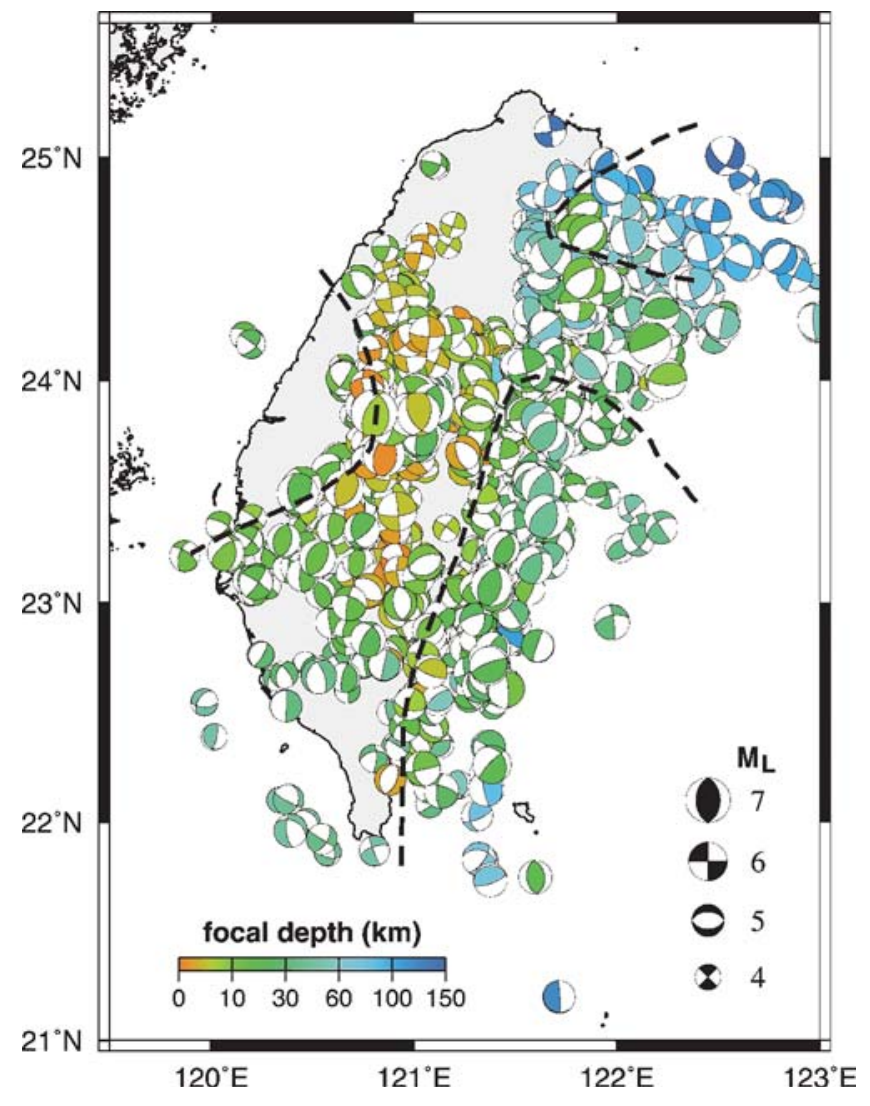

Figure 8. Focal mechanisms of $1635 M_{\mathrm{L}} \geq 4.0$ earthquakes determined in $\mathrm{Wu}$, Zhao, et al. (2008).

Finally, Figure 11 shows the distribution of the station corrections to the $P$-wave arrival times and the $S$ - $P$ times. There is an apparent correlation between the patterns of the station corrections and the geological settings, in particular, in the pattern of the $S$ - $P$ times. In our tomography study (Wu, Chang, et al., 2007), we have iteratively inverted for the $V_{P}$ and $V_{P} / V_{S}$ structures, the earthquakes locations and the station corrections, using 17,206 regional earthquakes. In that result, all of the station corrections were close to zero. In the current earthquake relocation study, the station corrections to the $P$-wave arrival times for the 264,708 earthquakes are still close to zero: the CWBSN station correction on average is $0.03-0.08 \mathrm{sec}$, and the correction for the $18 \mathrm{JMA}$ stations is $0.12 \pm 0.22 \mathrm{sec}$. The larger average correction for the JMA stations can be attributed to the fact that the tomography model has been obtained without using the JMA stations. In addition, stations in the southernmost part of Taiwan and the offshore region also have relatively large $P$-wave arrival time corrections because of relatively poor station coverage there. The quality of the earthquake locations and the resolution of the tomography inversion are relatively poor in those regions. The positive station corrections to the $P$-wave arrival times in most of the stations (blue dots) in and east of the Central Ranges imply that the actual $P$ waves arrive later than the $P$ waves predicted by the 3D tomography model. These $P$-wave delays at stations in

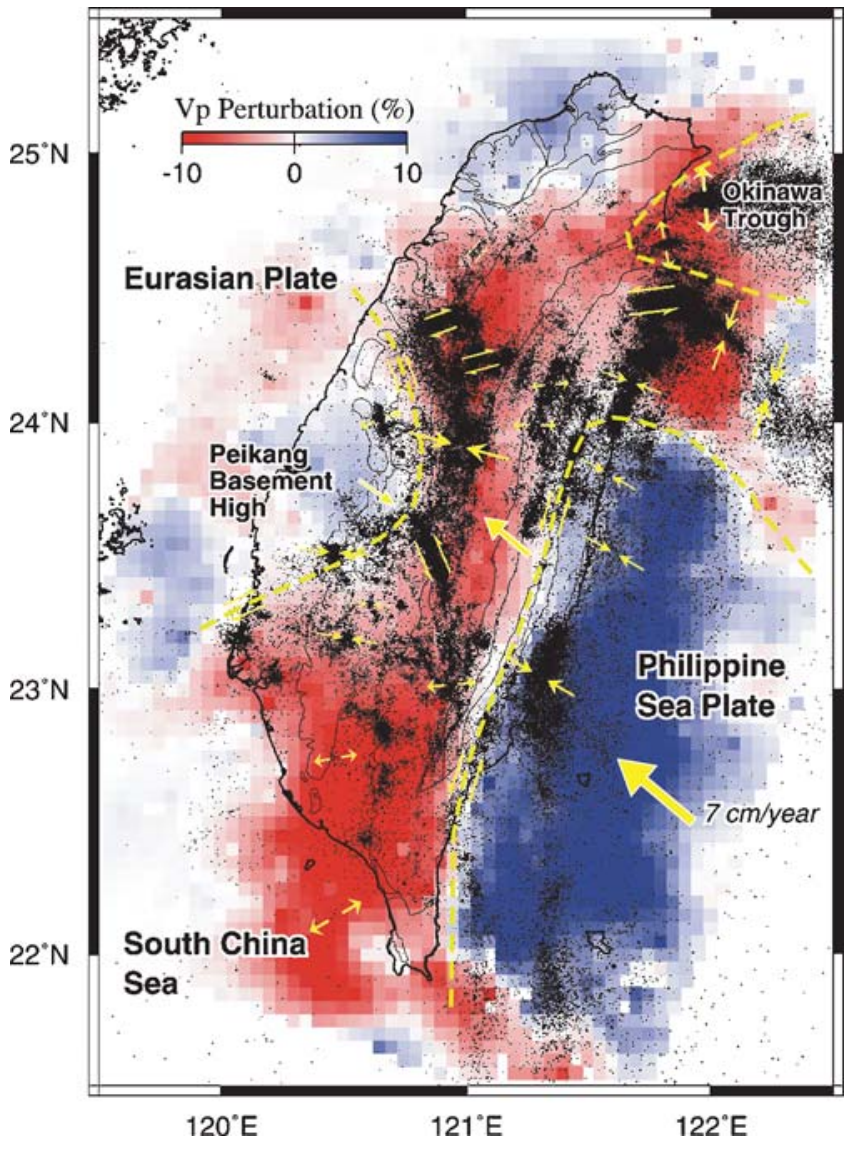

Figure 9. A composite map showing the $V_{P}$ perturbation (colors) at the depths between 17 and $21 \mathrm{~km}$, the epicenters (dots) of $M_{\mathrm{L}} \geq 2.0$ earthquakes relocated in this study, and the simplified stress description (small yellow arrows) from focal mechanisms.

the mountainous regions can be attributed to the elevations of the stations.

The station corrections to the $S-P$ times $(0.05 \pm$ $0.15 \mathrm{sec}$ ) are overall larger in comparison to those for $P$ waves due to the intrinsic higher uncertainty in picking the $S$-wave arrival time. Nevertheless, the pattern of the corrections to $S$-P times apparently correlates well with the surface geology, especially with the thickness of the sedimentary deposits in the top layer of the crust: negative corrections to $S-P$ times (red dots) are more commonly seen at stations near foothill locations, whereas farther away from the foothills and closer to the coast, the corrections to $S$ - $P$ times are mostly positive (blue dots). We also found three seemingly anomalous stations with large positive corrections to $S$-P times in the foothill region in southwestern Taiwan (black circle in Fig. 11). A careful examination of the local geology reveals that the three stations are all located in a region of mud formation that may have led to the large positive station corrections to $S-P$ times. The pattern of the station corrections to $S$ - $P$ times shows that this type of correction is very sensitive to shallow structure or site condition at the station, which cannot be absorbed easily either by the 3D model in tomographic inversions or by the 3D relocations of earth- 
(A) CWBSN 1D

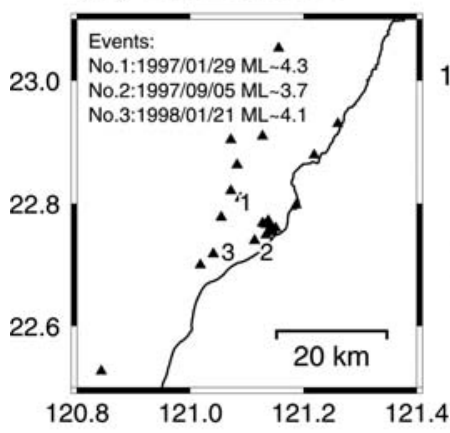

(C) CWBSN 3D
(B) CWBSN+TSMIP 1D
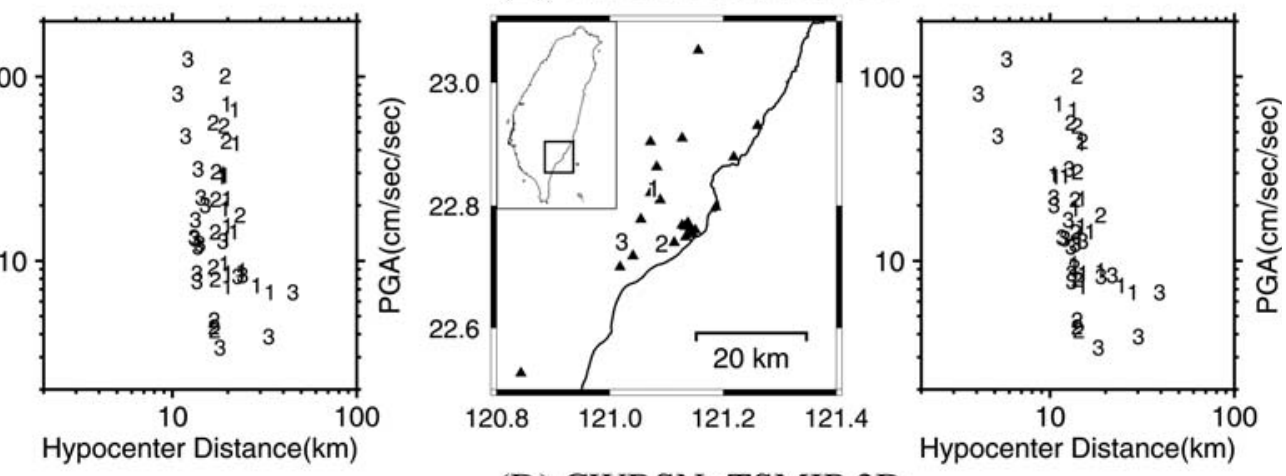

(D) CWBSN+TSMIP 3D
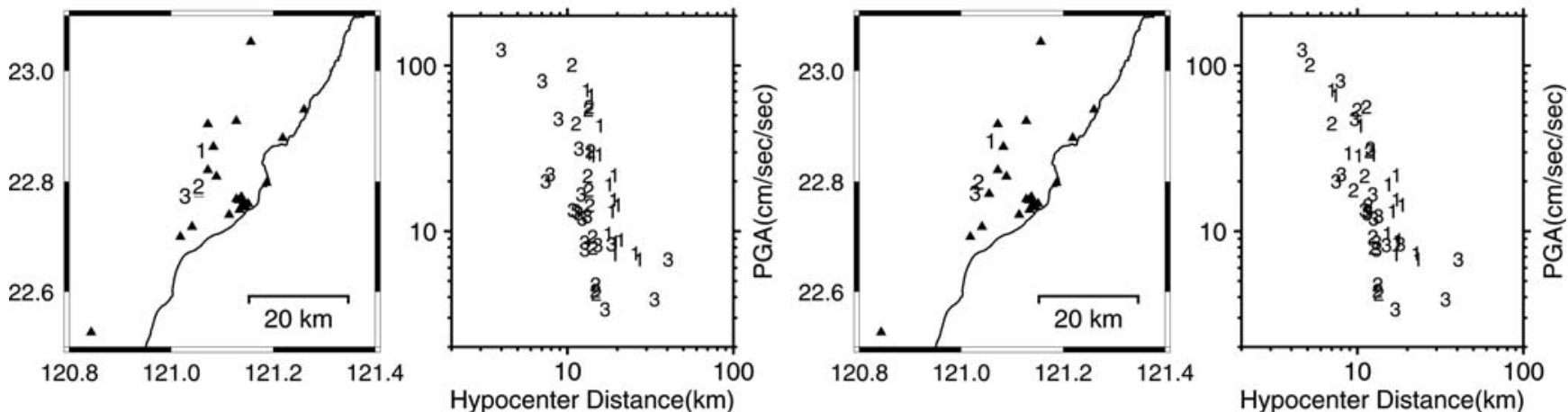

Figure 10. Locations and their PGA distributions of three earthquakes in the Taitung region determined by four different location processes.
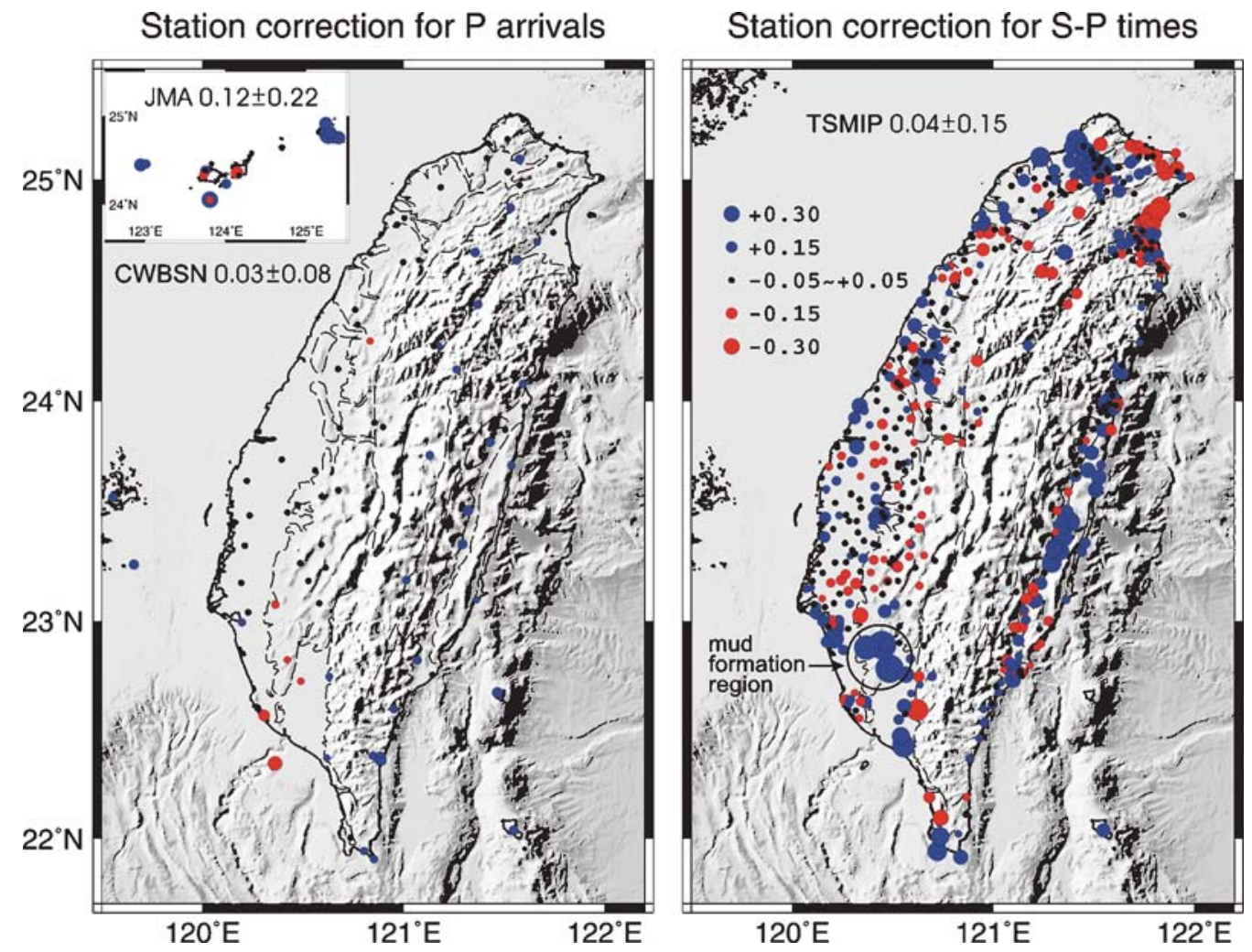

Figure 11. Distributions of the station corrections for $P$ arrivals and $S-P$ times determined in this study. 
quakes. More localized and targeted research is needed in the future to conclusively determine the exact nature of the individual station corrections.

\section{Conclusion}

In this study, we combined the $P$ - and $S$-wave arrival times from the CWBSN, TSMIP, and JMA stations to relocate a total of 267,210 earthquakes from 1991-2005 in the Taiwan region. Our relocation results show that the inclusion of the $S$-P times from the 680 TSMIP stations greatly improves the location accuracy for earthquakes on the Taiwan Island. The addition of the JMA stations in the southern Ryukyu Islands is important in locating earthquakes occurring off the northeastern coast. The adoption of the 3D tomography model further enhances the accuracy and reliability in the earthquake location results. The effectiveness of the relocation results can be seen in three aspects: the reduction in the residuals of $P$-wave arrival times and $S$ - $P$ times (Fig. 3), a better attenuation relationship between the peakground acceleration versus the epicentral distance (Fig. 10), and the geologically meaningful patterns of station corrections to $P$-wave arrival times and $S$ - $P$ times. (Fig. 11).

In previous studies, subsets of the events involved in this study have been used to conduct 3D tomography inversions for $V_{P}$ and $V_{P} / V_{S}$ structures in the Taiwan region ( $\mathrm{Wu}$, Chang, et al., 2007) and to determine the focal mechanisms of a number of relatively large earthquakes (Wu, Zhao, et al., 2008). The relocated events, along with the results in previous studies, provide a comprehensive archive for detailed seismological and tectonic investigations in the Taiwan region.

\section{Acknowledgments}

The authors wish to thank the Japan Meteorological Agency (JMA) for providing the arrival time data of JMA stations. Comments by two anonymous reviewers and the Associate Editor helped improve the manuscript. This work was supported by the Taiwan Earthquake Research Center (TEC) funded through National Science Council (NSC) under Grant Numbers NSC95-2625-Z-002-028, NSC95-2119-M-002-043-MY3, NSC95-2119-M -001-063, and NSC96-2116-M-001-011. The TEC contribution number for this article is 00026 . C. H. C. was also supported by the Central Weather Bureau of the Republic of China and Y. M. W. was also supported by the Tectonics Observatory of California Institute of Technology.

\section{References}

Big, C. (1965). The east Taiwan rift, Petrol. Geol. Taiwan 4, 93-106. Chang, S. H., and W. H. Wang (2006). Mechanical properties, slip and nucleation of the 1999 Chia-Yi earthquake: the question of static stress influence from the 1999 Chi-Chi earthquake, TAO 17, 331-343.

Chang, C. H., Y. M. Wu, T. C. Shin, and C. Y. Wang (2000). Relocating the 1999 Chi-Chi earthquake, Taiwan, TAO 11, 581-590.

Chang, C. H., Y. W. Wu, L. Zhao, and F. T. Wu (2007). Aftershocks of the 1999 Chi-Chi, Taiwan, earthquake: the first hour, Bull. Seismol. Soc. Am. 97, 1245-1258, doi 10.1785/0120060184.

Chen, C. C. (2003). Accelerating seismicity of moderate-sized earthquakes before the 1999 Chi-Chi, Taiwan, earthquake: testing time-prediction of self-organizing spinodal model of earthquakes, Geophys. J Int. 155, F1-F5.

Chen, Y. L. (1995). A study of 3-D velocity structure of the crust and the subduction zone in the Taiwan region, Master's Thesis, National Central University, Chungli City, Taiwan, 1972 pp. (in Chinese)

Chen, K. C., B. S. Huang, K. L. Wen, H. C. Chiu, Y. T. Yeh, S. N. Cheng, H. Y. Peng, T. M. Chang, T. C. Shin, R. C. Shih, and C. R. Lin (1999). A study of aftershocks of the 17 July 1998 Ruey-Li, Chiayi earthquake, TAO 10, 605-618.

Chen, H. Y., L. C. Kuo, and S. B. Yu (2004). Coseismic movement and seismic ground motion associated with the 31 March 2002 Hualien "331" earthquake, TAO 15, 683-695.

Chen, C. C., W. C. Wang, Y. F. Chang, Y. M. Wu, and Y. H. Lee (2006). A correlation between the $b$-value and the fractal dimension from the aftershock sequence of the 1999 Chi-Chi, Taiwan, earthquake, Geophys. J Int. 167, 1215-1219.

Chou, H. C., B. Y. Kuo, S. H. Hung, L. Y. Chiao, D. Zhao, and Y. M. Wu (2006). The Taiwan-Ryukyu subduction-collision complex: folding of a viscoelastic slab and the double seismic zone, J. Geophys. Res. 111, B04410, doi 10.1029/2005JB003822.

Ho, C. S. (1999). An Introduction to the Geology of Taiwan. Explanatory Text of the Geologic Map of Taiwan, Central Geological Survey/The Ministry of Economic Affairs, Taiwan.

Hu, J. C., L. W. Cheng, H. Y. Chen, Y. M. Wu, J. C. Lee, Y. G. Chen, K. C. Lin, R. J. Rau, H. Kuochen, H. H. Chen, S. B. Yu, and J. Angelier (2007). Coseismic deformation revealed by inversion of strong motion and GPS data: the 2003 Chengkung earthquake in eastern Taiwan, Geophys. J. Int. 169, 667-674, doi 10.1111/j.1365-246X.2007 .03359.x.

Johnson, K. M., P. Segall, and S. B. Yu (2005). A viscoelastic earthquake cycle model for Taiwan, J. Geophys. Res. 110, B10404, doi 10.1029/ 2004JB003516.

Kim, K. H., J. M. Chiu, J. Pujol, K. C. Chen, B. S. Huang, Y. H. Yeh, and P. Shen (2005). Three-dimensional $V_{P}$ and $V_{S}$ structural model associated with the active subduction and collision tectonics in the Taiwan region, Geophys. J. Int. 162, 204-220.

Kuochen, H., Y. M. Wu, C. H. Chang, J. C. Hu, and W. S. Chen (2004). Relocation of the eastern Taiwan earthquakes and its tectonic implications, TAO 15, 647-666.

Lee, W. H. K., and J. C. Lahr (1975). HYP071 (revised): a computer program for determining hypocenter, magnitude, and first motion pattern of local earthquakes, U.S. Geol. Surv. Open-File Rept. 75-311, $113 \mathrm{pp}$.

Lee, W. H. K., T. C. Shin, K. W. Kuo, K. C. Chen, and C. F. Wu (2001). CWB free-field strong-motion data from the 21 September Chi-Chi, Taiwan, Earthquake, Bull. Seismol. Soc. Am. 91, 1370-1376.

Lin, C. H. (2002). Active continental subduction and crustal exhumation: the Taiwan orogeny, Terra Nova 14, 281-287.

Ma, K. F., J. H. Wang, and D. Zhao (1996). Three-dimensional seismic velocity structure of the crust and uppermost mantle beneath Taiwan, J. Phys. Earth 44, 85-105.

Michael, A. J. (1984). Determination of stress from slip data-faults and folds, J. Geophys. Res. 89, 1517-1526.

Michael, A. J. (1987). Use of focal mechanisms to determine stressa control study, J. Geophys. Res. 92, 357-368.

Mouthereau, F., B. Deffontaines, O. Lacombe, and J. Angelier (2002). Variations along the strike of the Taiwan thrust belt: basement control on structural style, wedge geometry, and kinematics, Geol. Soc. Am. Spec. Paper 358, 31-54.

Rau, R. J., and F. T. Wu (1995). Tomographic imaging of lithospheric structures under Taiwan, Earth Planet. Lett. 133, 517-532.

Rundle, J. B., W. Klein, D. L. Turcotte, and B. D. Malamud (2000). Precursory seismic activation and critical-point phenomena, Pure Appl. Geophys. 157, 2165-2182.

Shin, T. C. (1992). Some implications of Taiwan tectonic features from the data collected by the Central Weather Bureau Seismic Network, Meteorol. Bull. 38, $23-48$ (in Chinese). 
Shin, T. C. (1993a). Progress summary of the Taiwan strong motion instrumentation program, in Proceeding of Symposium on Taiwan Strong Motion Instrumentation Program, Central Weather Bureau, Taipei, Taiwan, 1-10 (in Chinese).

Shin, T. C. (1993b). The calculation of local magnitude from the simulated Wood-Anderson seismograms of the short-period seismograms, TAO 4, 155-170.

Shin, T. C., and Y. L. Chen (1988). Study on the earthquake location of 3-D velocity structure in the Taiwan area, Meteorol. Bull. 42, 135-169.

Shin, T. C., and T. L. Teng (2001). An overview of the 1999 Chi-Chi, Taiwan, earthquake, Bull. Seismol. Soc. Am. 91, 895-913.

Shin, T. C., Y. B. Tsai, Y. T. Yeh, C. C. Liu, and Y. M. Wu (2003). Strongmotion instrumentation programs in Taiwan, in Handbook of Earthquake and Engineering Seismology, W. H. K. Lee, H. Kanamori and P. C. Jennings (Editors), Academic Press, New York, 1057-1602.

Shyu, J. B. H., K. Sieh, Y. G. Chen, and L. H. Chung (2006). Geomorphic analysis of the Central Range fault, the second major active structure of the Longitudinal Valley suture, eastern Taiwan, Geol. Soc. Am. Bull. 118, 1447-1462, doi 10.1130/B25905.1.

Suppe, J. (1984). Kinematics of arc-continent collision, flipping of subduction, and back-arc spreading near Taiwan, Mem. Geol. Soc. China 6, 21-33.

Teng, T. L., Y. B. Tsai, and W. H. K. Lee (2001). Preface to the 1999 Chi-Chi, Taiwan, earthquake dedicated issue, Bull. Seismol. Soc. Am. 91, 893-894.

Thurber, C. H. (1993). Local earthquake tomography: velocities and $V_{P} / V_{S}$-theory, in Seismic Tomography: Theory and Practice, H. M. Iyer and K. Hirahara (Editors), Chapman and Hall, London, $563-583$.

Thurber, C., and D. Eberhart-Phillips (1999). Local earthquake tomography with flexible gridding, Comput. Geosci. 25, 809-818.

Tsai, Y. B., T. L. Teng, J. M. Chiu, and H. L. Liu (1977). Tectonic implications of the seismicity in the Taiwan region, Mem. Geol. Soc. China 2 , 13-41.

Wu, Y. M., and C. C. Chen (2007). Seismic reversal pattern for the 1999 Chi-Chi, Taiwan, $M_{\mathrm{w}} 7.6$ earthquake, Tectonophysics 429, 125-132.

Wu, Y. M., and L. Y. Chiao (2006). Seismic quiescence before the 1999 Chi-Chi, Taiwan $M_{\mathrm{w}} 7.6$ earthquake, Bull. Seismol. Soc. Am. 96, 321-327.

Wu, Y. M., R. M. Allen, and C. F. Wu (2005). Revised $M_{\mathrm{L}}$ determination for crustal earthquakes in Taiwan, Bull. Seismol. Soc. Am. 95, 2517-2524.

Wu, Y. M., C. H. Chang, N. C. Hsiao, and F. T. Wu (2003). Relocation of the 1998 Rueyli, Taiwan, earthquake sequence using three-dimension velocity structure with stations corrections, TAO 14, 421-430.
Wu, Y. M., C. H. Chang, L. Zhao, J. B. H. Shyu, Y. G. Chen, K. Sieh, and J. P. Avouac (2007). Seismic tomography of Taiwan: improved constraints from a dense network of strong-motion stations, J. Geophys. Res. 112, B08312, doi 10.1029/2007JB004983.

Wu, Y. M., Y. G. Chen, C. H. Chang, L. H. Chung, T. L. Teng, F. T. Wu, and C. F. Wu (2006). Seismogenic structure in a tectonic suture zone: with new constraints from $2006 M_{\mathrm{w}} 6.1$ Taitung earthquake, Geophys. Res. Lett. 33, L22305, doi 10.1029/2006GL027572.

Wu, Y. M., Y. G. Chen, T. C. Shin, H. Kuochen, C. S. Hou, J. C. Hu, C. H. Chang, C. F. Wu, and T. L. Teng (2006). Coseismic vs. interseismic ground deformations, faults rupture inversion and segmentation revealed by $2003 M_{\mathrm{w}} 6.8$ Chengkung earthquake in eastern Taiwan, Geophys. Res. Lett. 33, L02312, doi 10.1029/2005GL024711.

Wu, Y.-M., L. Zhao, C.-H. Chang, and Y.-J. Hsu (2008). Focal-mechanism determination in Taiwan by genetic algorithm, Bull. Seismol. Soc. Am. 98, 651-661.

Yu, S. B., H. Y. Chen, L. C. Kuo, S. E. Lallemand, and H. H. Tsien (1997). Velocity field of GPS stations in the Taiwan area, Tectonophysics 274, 41-59.

Department of Geosciences

National Taiwan University

Taipei 10617, Taiwan

(Y.-M.W.)

Central Weather Bureau

Taipei 100, Taiwan

(C.-H.C.)

Institute of Earth Sciences

Academia Sinica

Taipei 11529, Taiwan

zhaol@earth.sinica.edu.tw

$$
\text { (L.Z., T.-L.T.) }
$$

Department of Physics and Earth Science

University of the Ryukyus

Okinawa, Japan

(M.N.)

Manuscript received 28 June 2007 